\title{
Nylon 4,I: an amorphous polyamide
}

\author{
R. J. Gaymans and A. G. J. Van der Ham \\ Twente University of Technology, Polymer Laboratories, PO Box 217, 7500 AE Enschede, \\ The Netherlands \\ (Received 20 January 1984; revised 6 March 1984)
}

\begin{abstract}
The melt polymerization of nylon 4, I was studied, starting with nylon-salt and nylon prepolymers $\left(\eta_{\text {inh }}=0.25\right)$. With nylon-salt only low molecular polymers were obtained, while with prepolymers the inherent viscosity could be raised to $0.77\left(3 \mathrm{~h}, 270^{\circ}\right.$, vac. $)$. The cyclization of tetra methylene diamine to pyrrolidine seem to be the major disturbing factor. The polymer is glassy and could easily be melt pressed. The torsion modulus of the material at $20^{\circ} \mathrm{C}$ was high $\left(1.810^{9} \mathrm{~Pa}\right)$ and remained high to near its $T_{g}\left(138^{\circ} \mathrm{C}\right)$.
\end{abstract}

(Keywords: tetra methylene diamine; isophthalic acid; nylon 4, I; amorphous nylon; polyamide synthesis; properties)

\section{INTRODUCTION}

Nylon 4,I is a polyamide which can be prepared from tetramethylene diamine (TMDA) and isophthalic acid (IA).

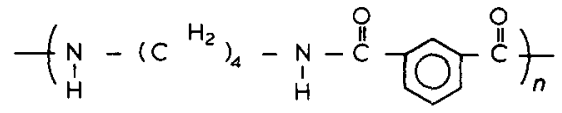

Poly(methylene isophthalamides) have been of interest for a long time ${ }^{1-7}$. They are all amorphous and combine a high glass transition temperature with a not too high melt processing temperature and a good solvent resistance. Lately one of these, nylon 6,1, has been brought on the market as an interesting new engineering plastic ${ }^{6,7}$ which has excellent high temperature properties $\left(T_{g}\right.$ $\left.121^{\circ} \mathrm{C}\right)$.

Nylon 4,I has an ever higher $T_{g}\left(141^{\circ} \mathrm{C}\right)^{3}$ and since little is known about this material an evaluation of its synthesis and its properties seemed relevant.

Poly(methylene isophthalamides) can be prepared from their nylon-salts ${ }^{4,6}$, or from a diamine and isophthalic dichloride $(\mathrm{ICl})^{1,2}$. For polyamides of the type AA-BB the synthesis from their salts is the most important method. The synthesis is carried out in two steps, (a) prepolymerization $\left(210^{\circ}-230^{\circ} \mathrm{C}\right)$ under pressure and (b) polymerization in the melt $\left(250^{\circ}-300^{\circ} \mathrm{C}\right)$ at atmospheric or reduced pressure. If the prepolymerization step is conducted at atmospheric pressure higher molecular weight compounds can be obtained ${ }^{4}$. In this case excess diamine is added to compensate for the loss of diamine due to volatilization. Another way of preparing nylons is with acid chlorides. These reactions can be carried out at low temperatures in solution or interfacially, the $\mathrm{HCl}$ being removed by an acid binder. By the solution polymerization with an aliphatic diamine the basicity of the acid binder can be the limiting factor in reaching a high molecular weight. With the interfacial method high molecular weight polyamides can easily be prepared ${ }^{1,2}$.

The synthesis of nylon 4,I is expected to be complicated by the low reactivity of the aromatic diacid ${ }^{8}$ and the possible cyclization of tetramethylene diamine to pyrrolidine.

$$
\begin{aligned}
& \mathrm{N}_{2} \mathrm{~N}-\left(\mathrm{CH}_{2}\right)_{4}-\mathrm{NH}_{2} \longrightarrow \square_{\mathrm{N}}+\mathrm{NH}_{3} \\
& T M D A \\
& \text { pyrrolidine }
\end{aligned}
$$

Pyrrolidine is a mono functional amine and can act as a chain terminator. For nylon 4,I only interfactial polymerizations have been reported ${ }^{1,2}$. Bonner $^{1}$ used a methylene chloride/water system and excess TMDA and obtained polymer with an inherent viscosity in $m$-cresol of 1.5. Gorton ${ }^{2}$ used a chloroform/water system and anhydrous sodium carbonate as acid binder. The polymer obtained by Gorton had an inherent viscosity in $m$-cresol of 1.55 .

The reported properties of nylon $4, I$ are a softening temperature at $230^{\circ} \mathrm{C}^{3}$, a melt temperature as measured on a gradient temperature bar at $230^{\circ}-245^{\circ} \mathrm{C}^{2}$ and with d.t.a. $\left(20^{\circ} \mathrm{C} / \mathrm{min}\right)$ a $T_{g}$ at $141^{\circ} \mathrm{C}$ and a $T_{m} 262^{\circ} \mathrm{C}^{3}$

A dry spun fibre which was crystallized in boiling water and drawn at $195^{\circ} \mathrm{C}$ had interesting fibre properties ${ }^{1}$. It is known that nylon $6, I$ can be synthesized in the melt ${ }^{6}$. The material is glassy and difficult to crystallize. It has $T_{q}$ at $120^{\circ} \mathrm{C}^{3,6}$ and a $T_{m}$ at $190^{\circ} \mathrm{C}$. It has excellent mechanical and dielectrical properties and a relatively low water absorption.

The aim of the present investigation was to synthesize nylon $4, I$ in the melt and to study some of its properties.

\section{EXPERIMENTAL}

\section{Monomers}

Isophthalic acid (IA), and tetramethylene diamine (TMDA) were obtained from Aldrich (Europe).

Isophthalic acid dichloride was synthesized from isophthalic acid and excess thionyl chloride and purified by vacuum distillation b.p. $64^{\circ} \mathrm{C}$ at $0.10 \mathrm{~mm} \mathrm{Hg}$.

\section{Nylon 4,I salt}

$50 \mathrm{ml}$ TMDA $(0.50 \mathrm{~mol})$ and $80 \mathrm{~g}$ IA $(0.48 \mathrm{~mol})$ were added to $250 \mathrm{ml}$ water with stirring. After some time a 
pale yellow solution was obtained from which the nylon salt was precipitated by adding $250 \mathrm{ml}$ ethanol. The white precipitate was filtered, washed with ethanol and ether and dried in a vacuum oven.

\section{Polymerization in an autoclave}

A $100 \mathrm{ml}$ stainless steel autoclave with a glass liner was charged with $25 \mathrm{~g}$ nylon $4, \mathrm{I}$ salt, $1.25 \mathrm{ml}$ water and excess TMDA. The autoclave was flushed with nitrogen and was given a starting pressure of 5 bar. The autoclave was heated up to $200^{\circ} \mathrm{C}$ and kept at that temperature for $1 \mathrm{~h}$, during which time the pressure increased to 15 bar. Then the temperature was raised to $250^{\circ} \mathrm{C}$ and the pressure reduced to $1 \mathrm{bar}$. The heating was continued for $1 \mathrm{~h}$ after which the autoclave was allowed to cool.

\section{Polymerization at atmospheric pressure}

A $50 \mathrm{ml}$ round bottom flask with condenser was charged with $10 \mathrm{~g}$ nylon 4,1 salt, $3-7 \mathrm{ml}$ water and excess TMDA. The reaction mass was heated over a period of $90 \mathrm{~min}$ to $270^{\circ} \mathrm{C}$ and kept at this temperature for $3 \mathrm{~h}$.

\section{Solution polymerization with $\mathrm{ICl}$}

$6.09 \mathrm{~g}$ Solid $\mathrm{ICl}(0.030 \mathrm{~mol})$ and a $100 \mathrm{ml}$ solution of $13.4 \mathrm{~g} N, N^{\prime}$-dimethylbenzylamine $(0.084 \mathrm{~mol}), \quad 2.67 \mathrm{~g}$ TMDA $(0.0303 \mathrm{~mol})$ in freshly distilled $N$-methylpyrrolidine were mixed in a $250 \mathrm{ml}$ flask under $\mathrm{N}_{2}$ and the reaction mass stirred for two hours during which time the solution turned cloudy. The polymer was precipitated in water, filtered, washed with water and methanol and dried.

\section{Postcondensation of prepolymers in the melt}

Prepolymer, $5 \mathrm{~g}\left(\eta_{\mathrm{inh}} 0.1-0.25\right)$ was heated in a glass flask to $270^{\circ}-290^{\circ} \mathrm{C}$ and kept at that temperature for $3 \mathrm{~h}$.

\section{Characterization}

Amine endgroups were determined by potentiometric titrations in phenol/water at $22^{\circ} \mathrm{C}$. Carboxyl endgroups were determined potentiometrically in benzylalcohol at $22^{\circ} \mathrm{C}$ after dissolving the polymer at higher temperatures.

The pyrrolidine endgroups were determined in hydrolysed samples by gas chromatography ${ }^{9}$. To hydrolyse the polymer $0.06 \mathrm{~g}$ material and $0.5 \mathrm{ml} 6 \mathrm{~N} \mathrm{HCl}$ in a sealed tube under $\mathrm{N}_{2}$ were heated for $10 \mathrm{~h}$ in an oil bath at $130^{\circ} \mathrm{C}$. After cooling $0.2 \mathrm{ml}$ of the supernatent liquid was withdrawn and treated with $0.7 \mathrm{ml} 2 \mathrm{~N}$ alcoholic sodium hydroxide solution to remove the amines. The gas chromatography analyses of $1 \mu \mathrm{l}$ of this solution was carried out using a preconditioned chromasorb (RTM) 130 column $1.5 \mathrm{~m} \times 0.6 \mathrm{~cm}$. From the ratio of the TMDA and pyrrolidine peaks and a knowledge of the approximate TMDA concentration in the polymer the pyr- rolidine concentration can be calculated from

$$
\frac{\text { [pyrrolidine] }}{\text { TMDA }} \times \frac{1000}{218}
$$

The $\eta_{\text {inh }}$ were determined using $0.5 \%$ solutions in $90 \%$ formic acid. The density of the solid polymer was determined in a hexane-tetra chloromethane mixture.

The ground polymer, dried for $24 \mathrm{~h}$ at $100^{\circ} \mathrm{C}$ in a vacuum oven, was melt pressed at $270^{\circ} \mathrm{C}$ and cooled at $20^{\circ} \mathrm{C} \mathrm{min}^{-1}$. D.t.a.-studies were conducted on a DuPont 990 Thermal Analyser at a heating rate of $20^{\circ} \mathrm{C} \mathrm{min}^{-1}$. Torsion pendulum analysis was conducted on a dried $\left(24 \mathrm{~h}\right.$ at $100^{\circ} \mathrm{C}$ ) sample at a constant frequency of $0.215 \mathrm{~Hz}$ and a heating rate of $1^{\circ} \mathrm{C} \mathrm{min}^{-1}$.

\section{RESULTS AND DISCUSSION}

\section{Polymerization}

Synthesis from nylon 4,I-salt. The results of the polymerization using variable amounts of diamine are shown in Table 1. The reaction products were all of a low molecular weight, due in part to the acid-amine imbalance but mainly due to the high pyrrolidine concentration.

Increasing the amount of diamine resulted in an improvement in the amine-acid balance and at the same time a lowering of the pyrrolidine concentration.

The loss of amine endgroups was large in all samples due to cyclization and evaporation of the diamine. In sample 4 both amine and acid endgroups are high suggesting that the rate of polymerization must have been low. The pyrrolidine concentration was high in all samples and with such pyrrolidine concentrations a high molecular weight can never be reached.

Polymerization at 1 bar with $1 \%$ catalyst (ammonium phosphate) and a heating programme (composed of warming up from room temperature to $270^{\circ} \mathrm{C}$ in $90 \mathrm{~min}$ and then heating for $3 \mathrm{~h}$ at $270^{\circ} \mathrm{C}$ ) also gave low viscosity polymers (Table 2). The endgroup analyses showed that there had been enormous amine loss and in order to obtain balanced amine-acid endgroups a much higher amine concentration should be employed at the start. The pyrrolidine concentration in these samples was relatively low.

Syntheses with isophthaloyl chloride. The syntheses of nylon 4,I was also studied by solution polymerization using ICl in NMP as solvent and $N, N^{\prime}$-dimethylbenzylamine as acid acceptor. In these experiments the concentration of the reactants and the excess diamine were varied (Table 3). The reactants with the lowest concentration of reactants $\left(0.15 \mathrm{~mol} \mathrm{l}^{-1}\right)$ remained clear while the higher concentrations turned cloudy and gelatinous. This turbidity had little effect on the molecular weights, which were low. The concentration of amine

Table 1 Two step melt polymerization with nylon 4,I salt

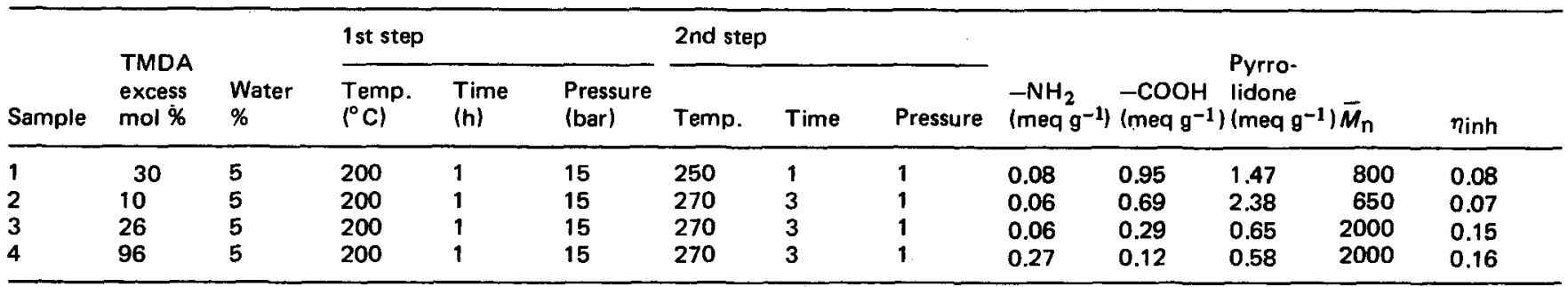


Nylon 4,I: an amorphous polyamide: R. J. Gaymans and A. G. J. Van der Ham

Table 2 Polymerization at 1 bar with nylon $4, \mathrm{I}$ salt (warming up to $270^{\circ} \mathrm{C}$ in $90 \mathrm{~min}$ and $3 \mathrm{~h}$ at $270^{\circ} \mathrm{C}$ )

\begin{tabular}{|c|c|c|c|c|c|c|c|c|}
\hline Sample & $\begin{array}{l}\text { TMDA } \\
\text { excess } \\
\text { mol\% }\end{array}$ & $\begin{array}{l}\text { Water } \\
\%\end{array}$ & $\begin{array}{l}\text { Pressure } \\
\text { (bar) }\end{array}$ & $\begin{array}{l}\mathrm{NH}_{2} \\
\left(\text { meq g }^{-1}\right)\end{array}$ & $\begin{array}{l}\mathrm{COOH} \\
(\mathrm{meq} \mathrm{g} \\
-1)\end{array}$ & $\begin{array}{l}\text { Pyrrolidone } \\
\left.\text { (meq } \mathrm{g}^{-1}\right)\end{array}$ & $\bar{M}_{\mathrm{n}}$ & $\eta_{\text {inh }}$ \\
\hline $\begin{array}{l}5 \\
6 \\
7\end{array}$ & $\begin{array}{r}2.5 \\
12.5 \\
17.5\end{array}$ & $\begin{array}{l}73 \\
30 \\
38\end{array}$ & $\begin{array}{l}1 \\
1 \\
1\end{array}$ & $\begin{array}{l}0.05 \\
0.08 \\
0.06\end{array}$ & $\begin{array}{l}0.69 \\
0.84 \\
0.48\end{array}$ & $\begin{array}{l}0.14 \\
0.10 \\
0.16\end{array}$ & $\begin{array}{l}2400 \\
2000 \\
2900\end{array}$ & $\begin{array}{l}0.15 \\
0.18 \\
0.23\end{array}$ \\
\hline
\end{tabular}

Table 3 Solution polymerization with isophthaloyl chloride in NMP at room temperature, followed by a postcondensation in the melt

\begin{tabular}{|c|c|c|c|c|c|c|c|c|c|c|c|}
\hline \multicolumn{9}{|c|}{ Solution polymerization } & \multicolumn{3}{|c|}{ Postcondensation in the melt } \\
\hline Sample & $\begin{array}{l}\text { Concen- } \\
\text { tration } \\
\left(\text { mol } 1^{-1}\right)\end{array}$ & $\begin{array}{l}\text { TDMA } \\
\text { mol eq. } \\
\text { excess }\end{array}$ & $\begin{array}{l}-\mathrm{NH}_{2} \\
\left(\mathrm{meq} \mathrm{g}^{-1}\right)\end{array}$ & $\begin{array}{l}-\mathrm{COOH} \\
\left(\mathrm{meq}^{-1}\right)\end{array}$ & $\begin{array}{l}\text { Pyr. } \\
(\text { meq g-1) }\end{array}$ & $\overline{M_{n}}$ & $\eta_{\text {rel }}$ & Remarks & $\begin{array}{l}3 \mathrm{~h} \\
\text { at } 270^{\circ} \mathrm{C} \\
1 \text { bar }\end{array}$ & $\begin{array}{l}3 \mathrm{~h} \\
\text { at } 270^{\circ} \mathrm{C} \\
0.02 \text { bar }\end{array}$ & $\begin{array}{l}3 \mathrm{~h} \\
\text { at } 290^{\circ} \mathrm{C} \\
0.02 \text { bar }\end{array}$ \\
\hline 8 & 0.3 & 0.0 & 0.06 & 0.76 & 0.01 & 2400 & 0.17 & Turbid solution & - & - & 0.59 \\
\hline 9 & 0.15 & 0.5 & 0.12 & 0.59 & 0.01 & 2800 & 0.21 & Clear solution & 0.54 & 0.77 & 0.73 \\
\hline 10 & 0.3 & 1.0 & 0.35 & 0.63 & 0.01 & 2000 & 0.18 & Turbid solution & - & - & 0.86 \\
\hline 11 & 0.3 & 2.3 & 0.20 & 0.38 & 0.01 & 3400 & 0.25 & Turbid solution & - & - & 0.74 \\
\hline
\end{tabular}

endgroups were lower than expected and also the extent of reaction was low.

Adding extra TMDA had a small effect on the molecular weight but it improved the amine-acid balance. More remarkable was the observation that in all these samples the pyrrolidine concentration was very low.

The mild reaction conditions made the syntheses of a prepolymer possible without the formation of pyrrolidine groups.

The postcondensation of these samples carried out in the melt at $270^{\circ}-290^{\circ} \mathrm{C}$ lead to higher molecular weight polymers (Table 3 ). The postcondensation at reduced pressure gave higher molecular weight materials than by reaction at 1 bar. Increasing the reaction temperature from $270^{\circ}$ to $290^{\circ} \mathrm{C}$ seemed to have little effect.

The dependance on the endgroup composition of the low molecular weight starting materials does not seem to be wholly logical. Sample 11 with the better amine-acid balance and the highest molecular weight gave, after postcondensation, a lower viscosity polymer than sample 10 (see Table 3).

Materials obtained by the solution polymerizationpostcondensation method had sufficiently high viscosities to make melt processing possible and to study some of their mechanical properties.

\section{Structure analyses}

Nylon 4,I in its extended planar form is not a good chain structure for close chain packing since the amide groups are situated so that optimal amide bonding is not possible. From this one can expect the crystallization rate and the crystallinity to be low.

The melt pressed samples were clear glasses (coloured brown) suggesting that under normal conditions they are amorphous. According to Bonner ${ }^{1}$ crystallization is possible in boiling water.

In the i.r. spectrum of a meltpressed film (Table 4) the low $\mathrm{N}-\mathrm{H}$ stretch at $3260 \mathrm{~cm}^{-1}$ and the low amide 1 band at $1620 \mathrm{~cm}^{-1}$ are particularly noteworthy. These suggest a very strong hydrogen bonding and a very short N $-\mathrm{H} \ldots \mathrm{O}=\mathrm{C}^{\prime} \quad$ bond distance, shorter than by aliphatic amides $\left(\mathrm{N}-\mathrm{H}\right.$ stretch a $\left.3300 \mathrm{~cm}^{-1}\right)$. This short

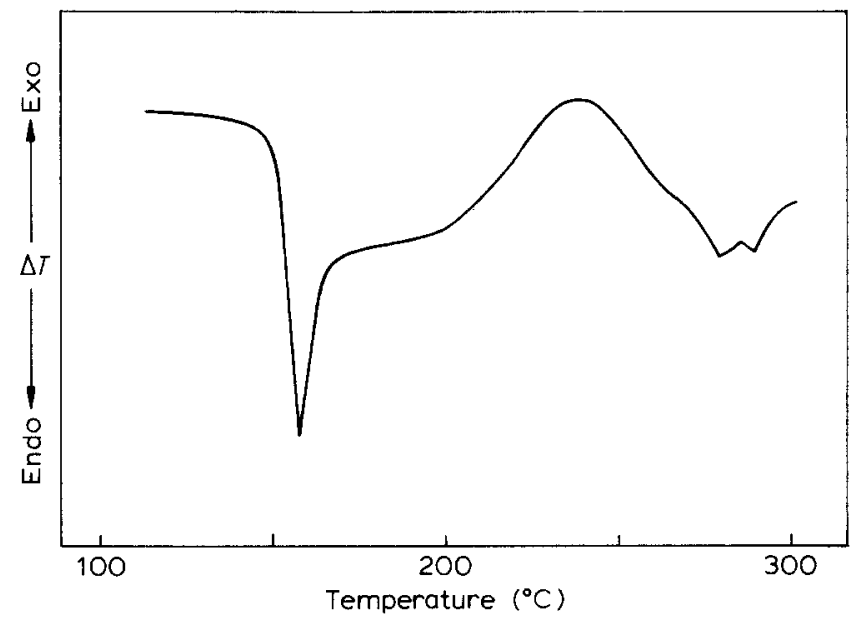

Figure 1 D.t.a. analysis on a meltpressed sample $20^{\circ} \mathrm{C} / \mathrm{min}$

hydrogen bond distance is only possible if the chains are not parallel but at an angle of $60^{\circ}-90^{\circ}$ with one and another, as observed with some diamides ${ }^{10.11}$.

\section{Properties}

The polymer $(\eta$ inh $=0.74$ could easily be melt processed and $1 \mathrm{~mm}$ thick sheets were melt pressed at $270^{\circ} \mathrm{C}$.

The density of the melt pressed sample conditioned at $65 \%$ RH (relative humidity) was $1.237 \mathrm{~g} / \mathrm{cm}^{3}$.

The water absorption of this nylon was at $65 \% \mathrm{RH} 3 \%$ and at $100 \% \mathrm{RH} 9 \%$. Which for an amorphous nylon with a high amide content is rather low.

The d.t.a.-analyses of the melt pressed polymer shows (Figure l) a second order transition at $146^{\circ} \mathrm{C}$ clearly the glass transition, an endothermic peak at $154^{\circ} \mathrm{C}$, a super heating peak due to enthalpic relaxation, an exothermic band at $200^{\circ}-260^{\circ} \mathrm{C}$ and an endothermic band at higher temperatures suggesting some crystallization and subsequent melting.

The thermal mechanical behaviour has been studied with a torsion pendulum apparatus on a dry sample and the results are given in Figure 2.

At room temperature the modulus is high; higher than that of aliphatic nylons and it remains high up to $135^{\circ} \mathrm{C}$. At the glass transition the modulus falls to very low 
Nylon 4,I: an amorphous polyamide: R. J. Gaymans and A. G. J. Van der Ham

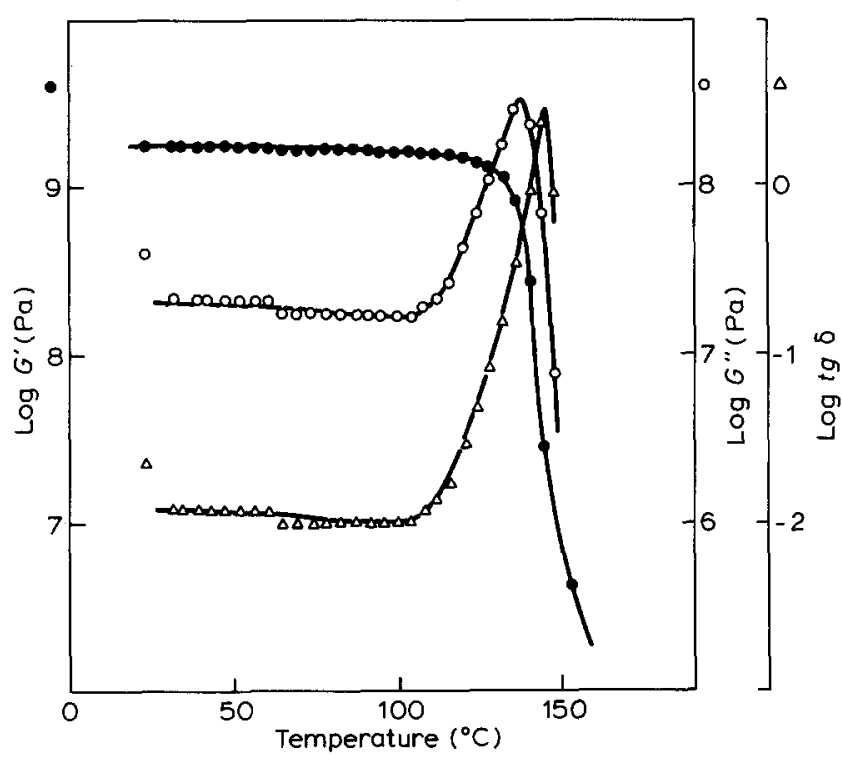

Figure 2 Torsion pendulum data of a dry sample; (O) $\log G^{\prime}$, (O) $\log G^{\prime \prime}$ and $(\triangle) \operatorname{tg} \delta$ at a frequency of $0.215 \mathrm{~Hz}$ and a heating rate of $9^{\circ} \mathrm{C} \mathrm{min} \mathrm{min}^{-1}$

values. The $G_{\max }^{\prime \prime}$ is at $138^{\circ} \mathrm{C}$ and the $\operatorname{tg} \delta_{\max }$ at $145^{\circ} \mathrm{C}$. This $G_{\max }^{\prime \prime}\left(\right.$ at $\left.1^{\circ} \mathrm{C} \mathrm{min}^{-1}\right)$ corresponds well with both the $146^{\circ} \mathrm{C}$ found with d.t.a. $\left(20^{\circ} \mathrm{C} \min ^{-1}\right)$ and the $141^{\circ} \mathrm{C}\left(20^{\circ} \mathrm{C}\right.$ $\min ^{-1}$ ) with d.s.c. reported by Morgan ${ }^{3}$.

\section{CONCLUSIONS}

Nylon 4,I is an amorphous polyamide which is difficult to synthesize. The synthesis from the nylon-salt is hampered by both the low reactivity of isophthalic acid as the cyclization of TMDA to pyrrolidine.

As yet no high molecular weight polymer could be synthesized from this nylon-salt.
The low temperature solution polymerization of $\mathrm{ICl}$ and TMDA offered low molecular weight polymers with a low pyrrolidine content. These samples could be post condensed in the melt at $270^{\circ} \mathrm{C}$ to higher molecular weights.

The structure of nylon $4 \mathrm{I}$ is so irregular that although its amide content is high it will crystallize only slowly.

The material could easily be melt processed and the melt pressed samples have glassy appearance.

The thermal mechanical behaviour of the material is excellent. It has a high modulus at room temperature and remains high up to its $T_{g}\left(138^{\circ} \mathrm{C}\right)$.

Nylon 4,I is a material with interesting engineering plastic and fibre properties.

\section{ACKNOWLEDGEMENTS}

The authors wish to thank Miss R. Smienk for her contribution on the syntheses and Dr F. H. J. Maurer (DSM, Geleen, The Netherlands) for studying the torsion properties.

\section{REFERENCES}

Bonner, W. H. US Pat. 3088794 (1963) to Du Pont Gorton, B. S. J. Appl. Polym. Sci. 1965, 9, 3753

Morgan, P. W. and Kwolek, S. L. Macromolecules 1975, 8, 104 Dolden, J. G. Polymer 1976, 17, 875

Jackson, J. B. Polymer 1969, 10, 159

Nielinger, W., Brassat, B. and Neuray, D. Angew. Makromol. Chem. 1981, 98, 225

7 Bayer, Vorläufiges Merkblatt 297/80, Durethan KLI-2104

8 Chapman, R. D., Holmer, D. A., Pickett, O. A., Lea, K. R. and Saunders, J. H. Text. Res. J. 1981, 51, 564

9 Gaymans, R. J. and Bour, E. H. J. P., Eur. Pat. 38094 (1981) to DSM

10 Harkema, S., Gaymans, R. J., Van Hummel, G. J. and Zylberlicht, D. Acta Crystallogr. 1979, B35, 506

11 Harkema, S., Gaymans, R. J. and Van Hummel, G. J. Acta Crystallogr. 1983, B39, 385 